\title{
$\beta$-noradrenergic receptor activation specifically modulates the generation of sighs in vivo and in vitro
}

\author{
Jean-Charles Viemari ${ }^{1}$, Alfredo J. Garcia III ${ }^{2,3+}$, Atsushi Doi ${ }^{2,3+}$, Gina Elsen ${ }^{2,3}$ and \\ Jan-Marino Ramirez ${ }^{2,3}$ \\ Team P3M, Institut de Neurosciences de la Timone, UMR 7289, CNRS, Aix Marseille Univesité, Marseille, France \\ ${ }^{2}$ Center for Integrative Brain Research, Seattle Children's Research Institute, Seattle, WA, USA \\ ${ }^{3}$ Departments of Neurological Surgery and Pediatrics, University of Washington School of Medicine, Seattle, WA, USA
}

Edited by:

Ronald M. Harris-Warrick, Cornell

University, USA

Reviewed by:

Paul A. Gray, Washington University,

USA

Gregory D. Funk, University of

Alberta, Canada

\section{*Correspondence:}

Jean-Charles Viemari, Team P3M,

Institut de Neurosciences de la

Timone, UMR 7289, CNRS, Aix

Marseille Université, 27 boulevard

Jean Moulin, 13385 Marseille

Cedex 05, France

e-mail: jean-charles.viemari@

univ-amu.fr

${ }^{\dagger}$ These authors have contributed equally to this work.
The pre-Bötzinger complex (preBötC), an area that is critical for generating breathing (eupnea), gasps and sighs is continuously modulated by catecholamines. These amines and the generation of sighs have also been implicated in the regulation of arousal. Here we studied the catecholaminergic modulation of sighs not only in anesthetized freely breathing mice (in vivo), but also in medullary slice preparations that contain the preBötC and that generate fictive eupneic and sigh rhythms in vitro. We demonstrate that activating $\beta$-noradrenergic receptors ( $\beta$-NR) specifically increases the frequency of sighs, while eupnea remains unaffected both in vitro and in vivo. $\beta$-NR activation specifically increased the frequency of intrinsically bursting pacemaker neurons that rely on persistent sodium current $\left(/_{\text {Nap }}\right)$. By contrast, all parameters of bursting pacemakers that rely on the non-specific cation current ( $\left.I_{\text {CAN }}\right)$ remained unaffected. Moreover, riluzole, which blocks bursting in / Nap pacemakers abolished sighs altogether, while flufenamic acid (FFA) which blocks the ICAN current did not alter the sigh-increasing effect caused by $\beta$-NR. Our results suggest that the selective $\beta$-NR action of sighs may result from the modulation of $I_{\text {Nap }}$ pacemaker activity and that disturbances in noradrenergic system may contribute to abnormal arousal response. The $\beta$-NR action on the preBötC may be an important mechanism in modulating behaviors that are specifically associated with sighs, such as the regulation of the early events leading to the arousal response.

Keywords: pacemaker neurons, respiratory rhythm, norepinephrine, neuromodulation, pre-Bötzinger complex, sigh rhythmic activity, in vivo

\section{INTRODUCTION}

The pre-Bötzinger Complex (preBötC) is a neural network that is critical for the generation of mammalian breathing (Ramirez et al., 1996; Tan et al., 2008; Schwarzacher et al., 2011). Isolated in transverse slices, this network continues to generate two distinct patterns of inspiratory activity that resemble those of eupnea and sigh activity (Lieske et al., 2000; Lieske and Ramirez, 2006a,b; Ruangkittisakul et al., 2008). Sighs or "augmented breaths" are large amplitude inspiratory efforts that regularly interrupt the fictive inspiratory pattern that in the intact animal represents eupnea. In the intact animal sighs maximally activate lung and chest wall mechano-receptors (Bendixen et al., 1964), and thus serve an important role in preventing atelectasis. Following vagotomy and sometimes following lesioning of the carotid sinus nerves, sighs are abolished for several hours (Bartlett, 1971; Glogowska et al., 1972; Matsumoto et al., 1997). But, sighs return after deafferentation and continue to be generated at a reduced frequency (Cherniack et al., 1981; Marshall and Metcalfe, 1988). These data suggest an important role for sensory feedback in modulating the drive to sigh but these experiments also indicate that reflexive mechanisms are not essential for their genesis. The characteristics

Abbreviations: preBötC, pre-Bötzinger complex; VRG, Ventral Respiratory Group. of fictive sigh-like bursts recorded in vitro are consistent with the definition of sighs in vivo (Glogowska et al., 1972; Cherniack et al., 1981; Orem and Trotter, 1993; Takeda and Matsumoto, 1998). In vivo and in vitro, the biphasic inspiratory activity has been described as a "eupneic-triggered sigh" since a eupneic respiratory burst typically proceeds and is coupled to the sigh (Lieske et al., 2000). Under certain conditions, however, sighs can also become uncoupled from the eupneic inspiratory activity (Lieske et al., 2000). Of particular importance is the role of sighs in the events that lead to arousal (Thach, 2002). In this context, failure to sigh and arouse has been implicated in the events that ultimately lead to Sudden Infant Death Syndrome (SIDS, Kahn et al., 1988).

The action of catecholamines on respiratory activity is subtype receptors specific (Viemari, 2008; Viemari et al., 2011). Interestingly, prior reports suggest that activation of $\beta$ noradrenergic receptors $(\beta-\mathrm{NR})$ has no significant effects on respiratory rhythmogenesis in the isolated neonatal brainstem preparation (Arata et al., 1998). Yet, the question whether different respiratory-related patterns are affected has not been addressed.

Here, we demonstrate that modulation of $\beta$-NR alters specifically sigh activity without affecting the eupneic respiratory pattern in vivo and in the in vitro medullary slice preparation. This 
indicates that both respiratory rhythms can be independently controlled by neuromodulators, which poses an interesting basicscientific problem: How can these two rhythmic activities with different timing characteristics (Lieske and Ramirez, 2006a,b; Ruangkittisakul et al., 2008; Tryba et al., 2008; Koch et al., 2013) be differentially controlled by neuromodulators? This is a particularly interesting problem, since the vast majority of neurons are synaptically connected during both rhythmic activities. Specifically, all respiratory neurons recorded in the study by Lieske et al. (2000) received phasic synaptic input during both activities. Another study suggested that more than $95 \%$ of neurons were synaptically connected to both rhythms and only less than $5 \%$ of the recorded respiratory neurons received synaptic input only during the sigh (Tryba et al., 2008). Thus, these data indicate that the network(s) involved in the generation of sighing and gasping is largely overlapping.

Here, we show that $\beta$-NR activation modulates bursting pacemaker neurons that depend on $I_{\mathrm{Nap}}$, while pacemakers that depend on $I_{\text {CAN }}$ remained unaffected. We also show that sighs were blocked by riluzole, an antagonist of $I_{\mathrm{Nap}}$, while they were unaffected by flufenamic acid (FFA), an antagonist of $I_{\mathrm{CAN}}$. Taken together, these data support the notion that heterogeneous cellular mechanisms differentially contribute to the generation of fictive eupneic and fictive sigh rhythms.

\section{MATERIALS AND METHODS THE TRANSVERSE SLICE PREPARATION}

Brainstem transverse slice preparation from CD1 mice (P6-P12) were obtained using a technique described in detail previously (Ramirez et al., 1996). The most important steps are summarized here. All surgical and experimental procedures conformed to guidelines from the French Ministry for Agriculture and Fisheries and were approved by the Institutional Animal Care and Use at the Seattle Children's Research Institute. The mice were anesthetized by hypothermia and decapitated. The isolated brainstem was then placed in ice-cold artificial cerebro-spinal fluid (a-CSF) bubbled with carbogen $\left(95 \% \mathrm{O}_{2}\right.$ and $\left.5 \% \mathrm{CO}_{2}\right)$. The aCSF contained (in $\mathrm{mM}$ ): $128 \mathrm{NaCl}, 3 \mathrm{KCl}, 1.5 \mathrm{CaCl}_{2}, 1 \mathrm{MgCl}_{2}$, $24 \mathrm{NaHCO}_{3}, 0.5 \mathrm{NaH}_{2} \mathrm{PO}_{4}$, and $30 \mathrm{D}$-glucose, $\mathrm{pH}$ of 7.4. The brainstem was then glued to an agar block on the mounting plate of a VT 1000 s (Leica Microsystems, Richmond Hill, ON, Canada) with the rostral end up and the ventral face toward the blade. 100 to $200 \mu \mathrm{m}$ Hundred to two hundred micrometers serial transversal slices at a $20^{\circ}$ angle were then made in a rostral to caudal direction until disapperance of parafacial group and appearance of the inferior olive, nucleus ambiguus, the hypoglossal nucleus, and the opening of the fourth ventricle as also described in the P0 atlas by (Ruangkittisakul et al., 2011). Then, a 550-650 $\mu \mathrm{m}$ thick a rhythmic slice containing the preBötC was made. The approach encompasses the preBötC (Figure 2). In this figure we cut the slice into three parts and stained the slices with NK1/DAPI antibodies (Figures 2C-E' ${ }^{\prime}$. The boundaries of NK1R+ cells in the ventral respiratory column correspond to $\sim 300 \mu \mathrm{m}$-thick sections in total. Note that the preBötC area shows a high concentration of NK1 staining (Figures 2C, $\mathbf{C}^{\prime}$ ) as previously described by different groups (Gray et al., 1999; Guyenet et al., 2002; Pagliardini et al., 2003). These slices also contain raphé neurons, Chx10 neurons
(Figures 3, 6; Crone et al., 2012) and TH-neurons important for the stabilization of the respiratory rhythm (Viemari et al., 2005; Zanella et al., 2006).

Slices are transferred into a recording chamber, continuously superfused with oxygenated a-CSF and maintained at a temperature of $30 \pm 0.5^{\circ} \mathrm{C}$. The potassium concentration of the perfusate was raised from 3 to $8 \mathrm{mM}$ over $30 \mathrm{~min}$ to ensure a long-lasting stable rhythm due to the duration of many of the protocols. It must be emphasized that a significant proportion of slices generates rhythmic activity already in $3 \mathrm{mM}$ potassium (Tryba et al., 2003).

\section{TISSUE PREPARATION AND HISTOLOGICAL ANALYSIS OF PREBÖtC}

As mentioned above, slice preparations from P7 CD-1 mice $(n=4)$ were processed for tissue histology. Briefly, $550 \mu \mathrm{m}$ transverse sections of the medulla encompassing the preBötC were fixed in cold buffered $4 \%$ paraformaldehyde (PFA) in $1 \times$ Phosphate Buffered Saline (PBS) overnight at $4^{\circ} \mathrm{C}$, frozen in optimum cutting temperature compound (OCT, VWR International, Radnor, PA, USA), cryostat sectioned at $14 \mu \mathrm{m}$ (for Nissl stain and immunofluorescence), and mounted on Superfrost Plus slides (Thermo Fisher Scientific, Waltham, MA, USA). Slidemounted sections were stored at $-80^{\circ} \mathrm{C}$ until needed. For Nissl staining, $14 \mu \mathrm{m}$ sections were stained with $0.5 \%$ cresyl violet, as previously described (Hevner et al., 2001). Immunofluorecence staining was done as previously described (Bedogni et al., 2010). Briefly, cryosections were air dried, washed three times in $1 \times$ PBS, blocked for $1 \mathrm{~h}$ at room temperature (RT) with $5 \%$ goat serum in PBS containing $0.3 \%$ Triton-X 100 and $0.2 \%$ bovine serum albumin (blocking solution) and then incubated overnight at $4^{\circ} \mathrm{C}$ with rabbit polyclonal anti-NK1R antibody (Advanced Targeting Systems, San Diego, CA, USA; 1:500). Species-specific fluorescent-tagged secondary antibody (Molecular Probes/Life Technologies, Grand Island, NY, USA; Alexa-Fluor-568 at 1:400 dilution) was applied for $2 \mathrm{~h}$ at RT, sections were counterstained with the nuclear label DAPI (0.01\%, Molecular Probes/Life Technologies, Grand Island, NY, USA) and coverslipped with microscope cover glass (Thermo Fisher Scientific, Waltham, MA, USA) using Fluormount-G (Southern Biotech, Birmingham, AL, USA). Mosaic images of Nissl stain and bright field live images at low magnification were obtained using a Zeiss Axioimager Z1 microscope with Axiovision v4.7 software (10× objective). Fluorescent images detecting NK1R antibody in the preBötC at high magnification were obtained using a Zeiss LSM 710 confocal microscope ( $40 \times$ objective, $543 \mathrm{~nm}$ laser line).

\section{DRUGS AND SOLUTIONS}

A cocktail of antagonists for NMDA-receptors [CPP-(RS) $10 \mu \mathrm{M}$, Tocris Cookson, Ellisville, MO], non-NMDA receptors (CNQX $20 \mu \mathrm{M}$, Tocris Cookson), glycine-receptors (strychnine $1 \mu \mathrm{M}$, SIGMA-RBI, St. Louis, MO) and $\mathrm{GABA}_{\mathrm{A}}$-receptors (bicucullinefree base $20 \mu \mathrm{M}$, SIGMA-RBI) was used to block fast synaptic transmission (Peña et al., 2004). Bicuculline free base used in the present study has a very different pharmacology than the commonly used bicuculline salts (e.g., bicuculline methiodide), and the free base does not block apamin-sensitive calciumactivated potassium currents (Seutin and Johnson, 1999). To 
block either $I_{\mathrm{Nap}}$ or $I_{\mathrm{CAN}}$, we bath-applied riluzole hydrochloride (riluzole $20 \mu \mathrm{M}$, Tocris Cookson, and SIGMA-RBI) or FFA (50-500 $\mu \mathrm{M}$, SIGMA-RBI), respectively. We used a wide range of FFA concentration since FFA is known for its non-specific actions (Guinamard et al., 2013). All drugs were initially solubilized in dimethylsulfoxide (DMSO, SIGMA-RBI). Norepinephrine (NE; Arterenol hydrochloride), prazosin hydrochloride (antagonist of $\alpha 1$-noradrenergic receptors; $\alpha 1-\mathrm{NR})$, yohimbine hydrochloride (antagonist of $\alpha 2$-noradrenergic receptors; $\alpha 2-\mathrm{NR}$ ), isoproterenol hydrochloride (agonist of $\beta$-NR) or propanolol (antagonist of $\beta$ NR) (SIGMA-RBI) was added to ACSF. Each drug was applied only once in a given slice, and only one slice was obtained per animal.

\section{In vivo ANESTHETIZED MOUSE PREPARATION}

CD1 mice (P9-P12) were anesthetized with urethane $(1.5 \mathrm{~g} / \mathrm{kg})$. To characterize the respiratory activity of these freely breathing mice, we obtained electromyography (EMG) recordings from intercostal muscles. The mice were placed in a supine position and the head was fixed within a stereotaxic apparatus. The neck of the mice was opened from the ventral side, the trachea was cut and a plastic Y-shaped tubing for supplying oxygen was inserted into the proximal end of the trachea ("cannulation"). The bone of the skull covering the ventral brainstem was partially removed. The dura and arachnoid membrane were removed to expose the ventral medulla. The surface of the ventral medulla was continuously superfused with $95 \% \mathrm{O} 2-5 \% \mathrm{CO} 2$ equilibrated aCSF solution at $30 \pm 0.5^{\circ} \mathrm{C}$. In all cases, $100 \%$ oxygen was supplied through the cannulation to avoid the need for artificial ventilation (Doi and Ramirez, 2010).

\section{MICROINJECTION STUDIES IN in vivo ANESTHETIZED MICE.}

Microsyringes (Hamilton microsyringe no. 80330) with 33 gauge needles containing NE agonist $30 \mu \mathrm{M}$ isoproterenol, total $0.6 \mu \mathrm{l}$ ) were positioned with micromanipulators (KITE, World Precision Instruments). The needles of the microsyringes were inserted into the right preBötC from the ventral side. During hypoglossal nerve recording or intercostal EMG recordings, these antagonists were microinjected into the right preBötC area at a rate of $0.3 \mu \mathrm{l} / \mathrm{min}$. We did not attempt to perform bilateral needle injections to limit the damage to the preBötC, which would have compromised respiratory rhythm-generating mechanisms. Identification of drug injection site has been performed as previously described (Doi and Ramirez, 2010). Control experiments were done and injection of aCSF $(\sim 300-400 \mathrm{~nL} / \mathrm{min})$ had no effect on respiratory stability or patterns $(n=4$, not shown).

\section{EXTRACELLULAR RECORDINGS}

In the transverse slice preparation population activity recordings were obtained with suction electrodes positioned on the surface of the slice in the area including the preBötC. The slice preparation is placed rostral side up and encompasses network components rostral to the preBötC that appear to be critical for generating the sigh rhythm in very thin slices (Ruangkittisakul et al., 2008). The signals were amplified 2000 times, filtered (low pass $1.5 \mathrm{KHz}$, high pass $250 \mathrm{~Hz}$ ), rectified and integrated using an electronic filter (time constant of 30-50 ms). Integrated population activity from the ventral respiratory group (VRG) was always in phase with integrated inspiratory activity of the hypoglossal motor nucleus (Telgkamp and Ramirez, 1999). Therefore, it was used as a marker for inspiratory population activity (Figure 1A). All recordings were stored on a personal computer using AxoTape (Version 2.0, Axon Instruments, Union City, CA) and analyzed offline using customized analysis software written with IGOR Pro (Wavemetrics, Lake Oswego, OR). Bursts were automatically detected by the IGOR program as described extensively in our previous study (Tryba et al., 2003; Viemari and Ramirez, 2006).

\section{EMG RECORDINGS}

Eupneic activity was characterized with rostral intercostal muscles EMG recordings. For this purpose we used teflon-coated Ag bipolar electrode. The teflone coating was removed at the recording surface of this electrode. The skin covering the abdominal and intercostal muscles on the right side was partially removed, and the bipolar electrode was placed on the surface of the intercostal muscles. Signals were AC amplified and band pass filtered (8-3 kHz) (Doi and Ramirez, 2010).

\section{INTRACELLULAR RECORDINGS}

A single intracellular recording was made from an inspiratory preBötC neuron (one neuron per slice) using the blind patchclamp recording method. Inspiratory neurons are first identified in the cell-attached mode, which reveals their discharge pattern in phase with population activity. The slice preparation is placed rostral side up and we recorded neurons that are located between 100 and $300 \mu \mathrm{m}$ from the surface, nor more superficial than $100 \mu \mathrm{m}$ to obtain neurons that are maximally connected within the respiratory network. Experiments were then performed in whole-cell configuration with the neuron recorded in currentclamp where holding current was $0 \mathrm{pA}$. It must be emphasized that we have previously demonstrated that the whole-cell configuration does not alter the firing pattern of the recorded neuron (Peña et al., 2004). The patch electrodes are pulled from filamented borosilicate glass tubes (G150F-4; Warner Instruments, Hamden, CT) and filled with a solution containing $140 \mathrm{mM} \mathrm{K}$ gluconic acid, $1 \mathrm{mM} \mathrm{CaCl}_{2}^{*} 6 \mathrm{H}_{2} \mathrm{O}, 10 \mathrm{mM}$ EGTA, $2 \mathrm{mM} \mathrm{MgCl}_{2}^{*}$ $6 \mathrm{H} 2 \mathrm{O}, 4 \mathrm{mM} \mathrm{Na} \mathrm{m}_{2} \mathrm{ATP}$, and $10 \mathrm{mM}$ HEPES. The composition of this intracellular solution and the lack of adverse effects on pacemaker activity was first demonstrated by our laboratory (Peña et al., 2004) and later reproduced by others (Del Negro et al., 2005). The K-gluconic acid-containing electrode solution resulted in a significant liquid junction potential $(12 \mathrm{mV})$, which affected measured membrane potentials. All membrane potential values were corrected for this liquid junction potential as described by (Neher, 1992).

\section{EVOKED SYNAPTIC TRANSMISSION}

Patch clamp recordings were made from rhythmically active preBötC neurons identified in a-CSF with $8 \mathrm{mM} \mathrm{KCl}$. Once a stable recording was established, the circulating media was switched from 8 to $3 \mathrm{mM} \mathrm{KC1} \mathrm{a-CSF}$ where rhythmically bursting neurons became quiescent. To assess changes in synaptic transmission the contralateral VRG was stimulated using bipolar stimulation (100-300 $\mu \mathrm{A} ; 150-450 \mu \mathrm{s}$; isolation unit, 
A1 Intercostal EMG activity

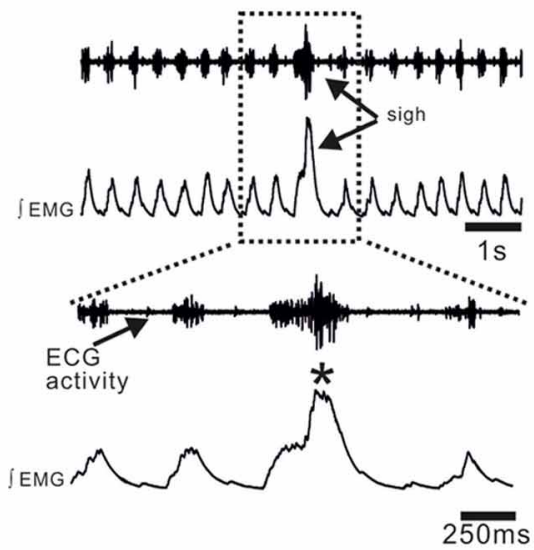

A2

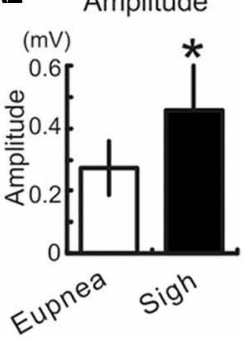

A4

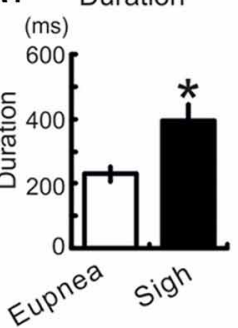

B

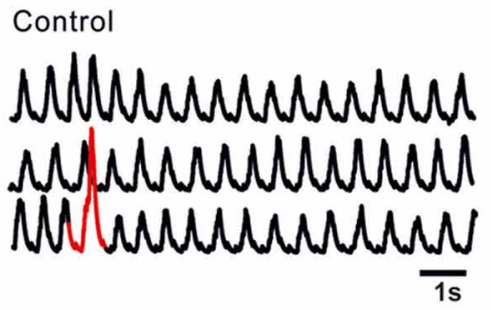

Isoproterenol $30 \mu \mathrm{M}$

EMG

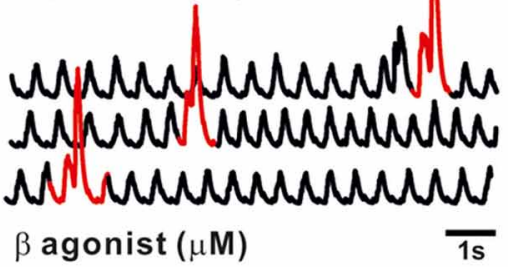

E

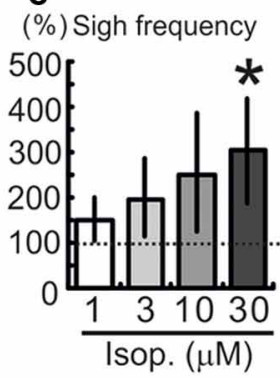

D

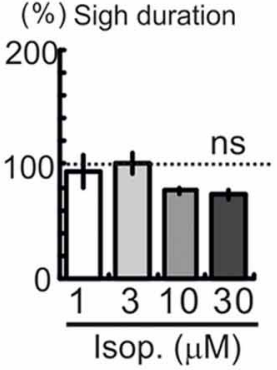

A3 Frequency $(\mathrm{Hz})$

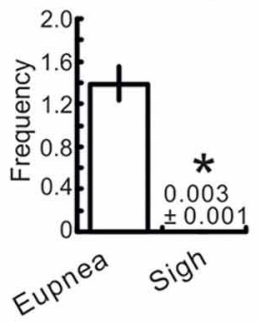


an effect on the different breathing patterns. Sighs are characterized by their large amplitude event that are triggered by a smaller eupneic event and are followed by a respiratory pause ("post-sigh apnea," Figures 1A1,A2). Sighs occur at a low frequency and have a longer duration compared with eupneic events $\left({ }^{*} p<0.05\right.$, Mann and Whitney test, Figures 1A3, A4). We injected isoproterenol $(1,3,10$, and $30 \mu \mathrm{M})$ unilaterally into the pre-BötC (Figure 1B). Isoproterenol at $30 \mu \mathrm{M}$ significantly enhanced the sigh frequency $\left({ }^{*} p<0.05\right.$, Friedman test, Figures1B-D) compared to control, but had no effect on the eupnea frequency (Figure 1E). Isoproterenol had no effect on the different patterns while used at a concentration lower than $30 \mu \mathrm{M}$ suggesting that no effect was due to pressure injection.

\section{ACTIVATION OF $\beta$-NR ENHANCES FICTIVE SIGH RHYTHMIC ACTIVITY IN THE TRANSVERSE SLICE PREPARATION}

As previously shown, the medullary respiratory network isolated within the medullary transverse slice preparation in vitro in mice (see Figures 2A-E, and methods for details) generates under control conditions two distinct types of fictive respiratory activities: eupneic inspiratory and sigh activity as defined by (Lieske et al., 2000; Ruangkittisakul et al., 2008; Tryba et al., 2008). Fictive sigh bursts occurred spontaneously (Figure 2F) at a frequency
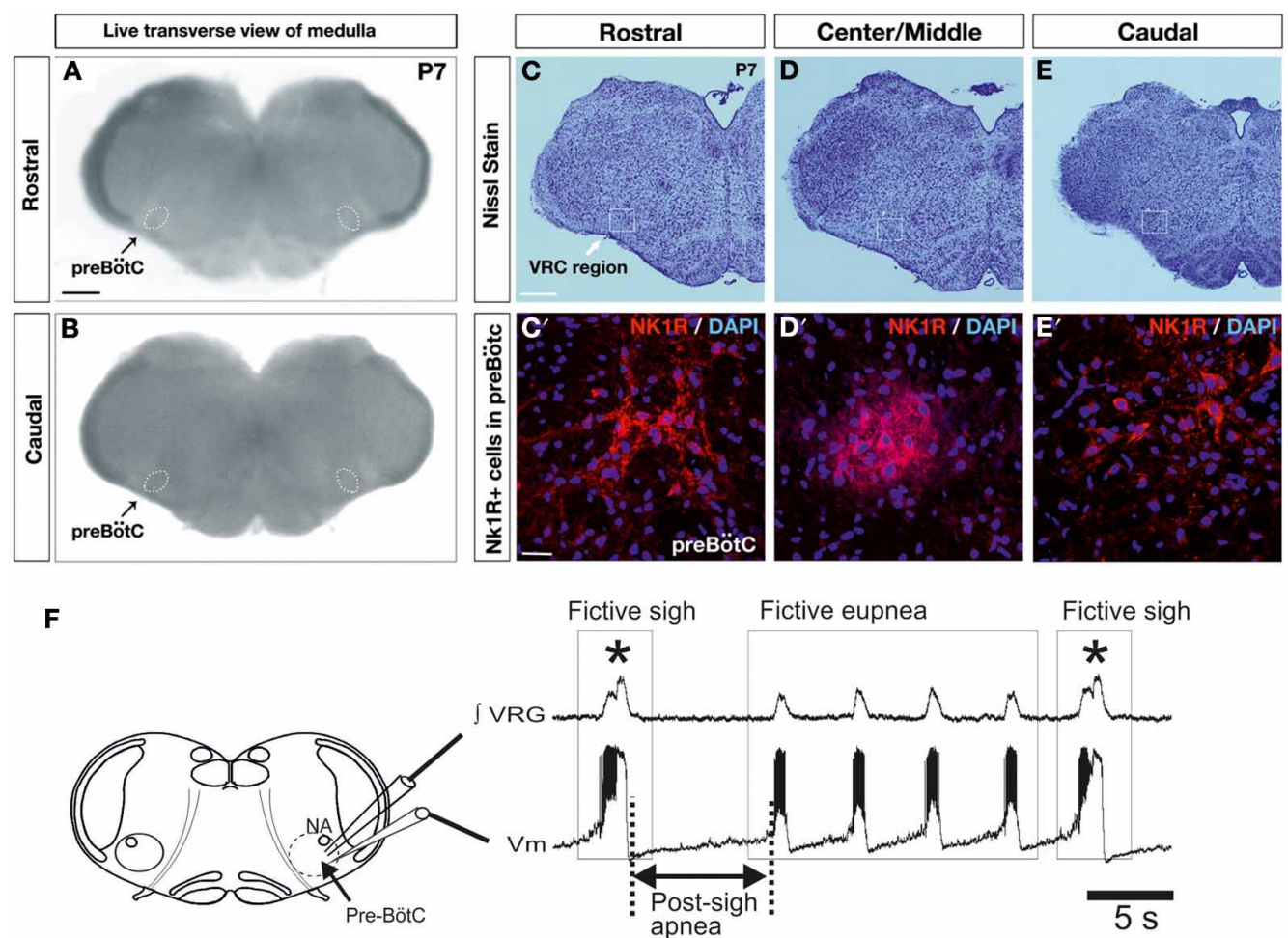

Fictive eupnea

Fictive sigh

G

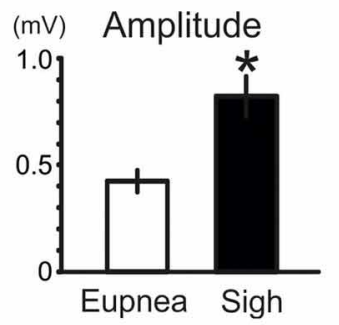

$\mathbf{H}$

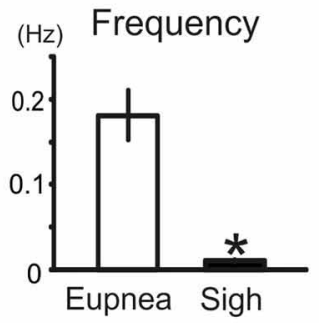

I

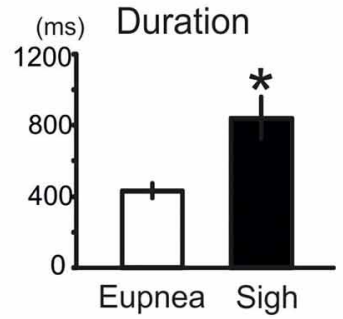

FIGURE 2 | Fictive sigh activity is observed in the in vitro transverse slice preparation. Anatomical characterization of the transverse slice preparation (P7 mouse): (A) rostral and (B) caudal surface of the same live transverse slice preparation. This representative slice preparation was cut into three sections and Nissl staining was used to characterize the rostral $\left(\mathbf{C}, \mathbf{C}^{\prime}\right)$ and caudal surface $\left(\mathbf{E}, \mathbf{E}^{\prime}\right)$, as well as the Center/Middle portion of the slice $\left(\mathbf{D}, \mathbf{D}^{\prime}\right)$. NK1+ and DAPI+ immunoreactive neurons are depicted in $\left(\mathbf{C}^{\prime}-\mathbf{E}^{\prime}\right)$. Note that NK1R staining, which is indicative of the preBötC, is most abundant in the center, but NK1R staining extends also into the rostral and caudal portions of the slice. (F) Schematic of the brainstem slice preparation including the anatomical landmarks of the preBötC and recording sites of integrated VRG activity ( $\int$ VRG upper trace) and whole-cell patch clamp recordings (membrane potential, $V m$, lower trace). Both traces depict fictive eupneic activity and fictive sigh activity recorded from a slice. Sighs are typically followed by a post-sigh apnea. Note that fictive sigh bursts occurred spontaneously at a slower frequency than fictive respiratory activity. Histograms summarize the significant differences between spontaneous sighs and fictive respiratory activity, in burst amplitude (G), in burst frequency (H) and burst duration (I). Results are expressed as mean \pm SE. Asterisk (*) shows significant differences. ( $\left.{ }^{*} p<0.05, n=18\right)$. 
of $0.01 \pm 0.001 \mathrm{~Hz}$, which is slower than the frequency of fictive eupneic inspiratory activity $0.18 \pm 0.03 \mathrm{~Hz}(n=18, P<0.0001$, Mann and Whitney test, Figure $2 \mathbf{H}$ ). Fictive sighs have a bi-phasic shape (Figure 1A1). They are larger in amplitude $(205 \pm 22 \%$ of control; $p<0.001$, Mann and Whitney test, Figure 2G), and longer in duration ( $198 \pm 20 \%$ of control, $p=0.0011$, Mann and Whitney test, Figure 2I) than the bursts associated with fictive eupneic inspiratory activity.

We previously reported that NE plays a major role in modulating respiratory rhythmogenesis (Viemari et al., 2004; Viemari, 2008). As illustrated in Figure 3A, NE enhanced the frequency of fictive inspiratory activity, but also sigh like activity $(670 \pm$ $120 \%, n=7, P<0.001$, Friedman test). Application of the $\alpha 1-\mathrm{NR}$ antagonist prazosin $(50 \mu \mathrm{M})$ prior to the NE application had no effect on baseline eupnea as previously reported (Viemari and Ramirez, 2006) and on baseline sigh like frequency. Moreover, prazosin did not affect the NE-mediated increase in sigh frequency $(745 \pm 270 \%, n=4$, Friedman test, Figures 3B,C) and duration (Figure 3D) suggesting that the
NE-induced increase in sigh activity frequency was not mediated by $\alpha 1-N R s$. Similarly, application of the $\alpha 2-N R$ antagonist yohimbine did not block the sigh-increasing effect of NE as sigh frequency was still increased ( $n=3$, data not shown). Application of the $\beta$-NR agonist isoproterenol $(20 \mu \mathrm{M})$ significantly increased the fictive sigh frequency by $400 \pm 65 \%(n=$ $10, P=0.0022$, Wilcoxon rank test, Figures $4 \mathrm{~A}, \mathrm{~B}, \mathrm{E})$ without affecting the fictive eupnea frequency ( $P=0.94$, Figure $4 \mathrm{C})$, the sigh amplitude $(P=0.28$, Wilcoxon rank test, Figure 4D) or the sigh duration ( $P=0.62$, Wilcoxon rank test, Figure 4F). Similarly, the duration of the fictive post-sigh apnea was not different in the presence of isoproterenol $(5.9 \pm 0.07 \mathrm{~s}$ vs. $6.1 \pm$ $0.1 \mathrm{~s}, n=12, P=0.63$, Wilcoxon rank test). Application of the $\beta$-NR antagonist propranolol $(50 \mu \mathrm{M}, n=4.4)$ prior to applying isoproterenol blocked the effect on fictive sighs, confirming that the modulation of sigh frequency involved specifically the activation of the $\beta$-NR (data not shown). From these results we conclude that $\beta$-NR preferentially modulate the fictive sigh rhythm.
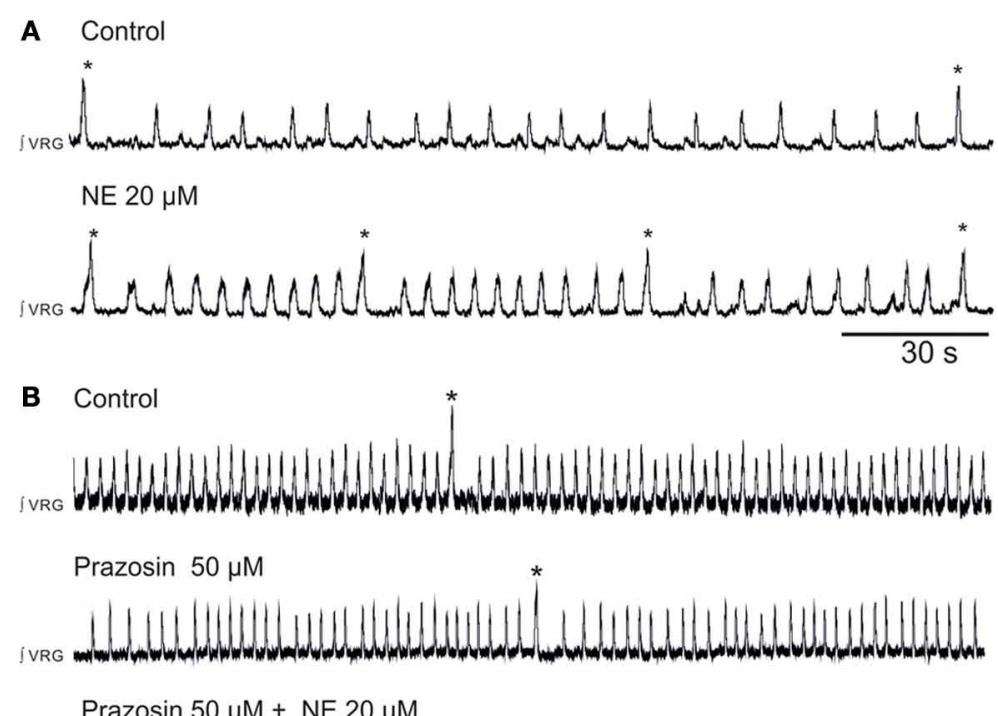

Prazosin $50 \mu \mathrm{M}+\mathrm{NE} 20 \mu \mathrm{M}$
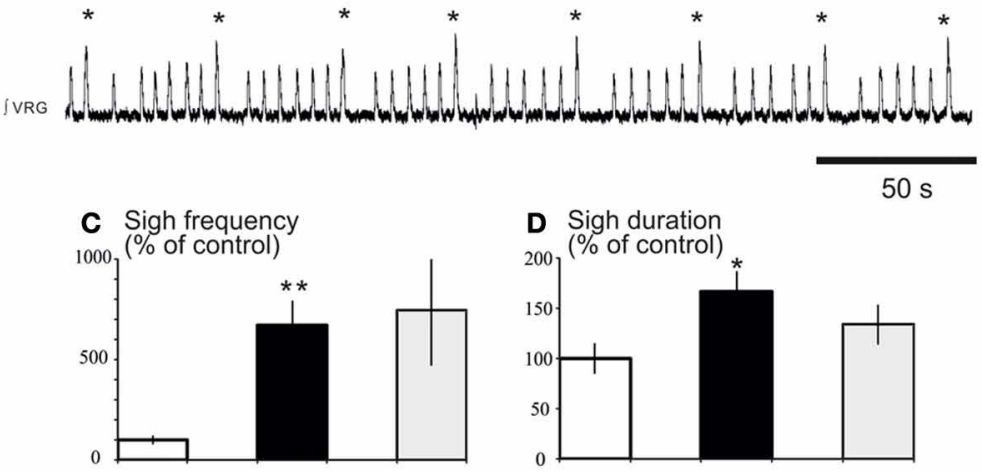

FIGURE 3 | Blockade of $\alpha$ 1-NR does not abolish the noradrenergic modulation of fictive sigh activity. (A) Application of NE $20 \mu \mathrm{M}$ increases the frequency of "fictive eupneic" respiratory activity as well as the sigh activity compared to control. (B) Blockade of $\alpha 1-\mathrm{NR}$ (prazosin $50 \mu \mathrm{M}$ ) abolishes the NE-induced increase in frequency of the fictive eupneic activity but not the increased in frequency of the sigh activity. (C,D) Histograms show the effects of NE + prazosin on sigh burst frequency (C) and the sigh burst duration (D) $\left({ }^{*} p<0.05, n=4\right.$; $\left.{ }^{* *} p<0.01\right)$. 


\section{A Control

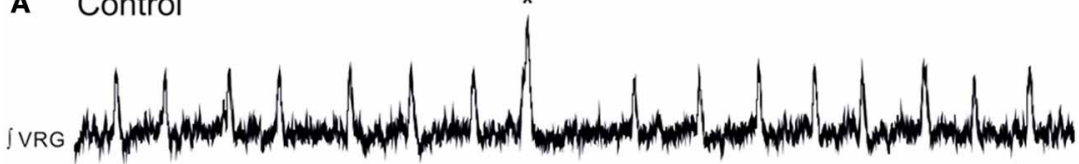

B Isoproterenol $20 \mu \mathrm{M}$

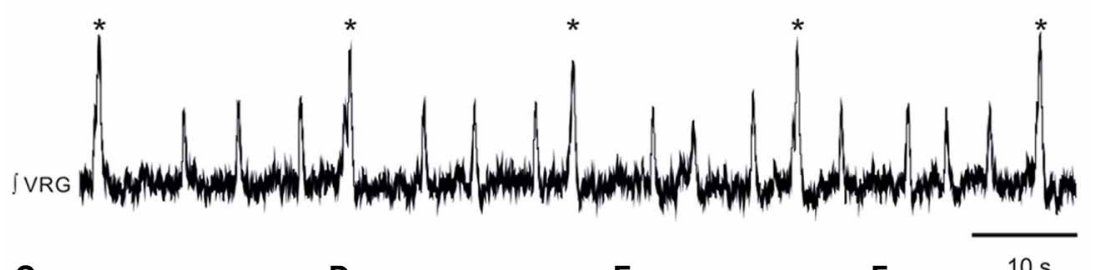

C

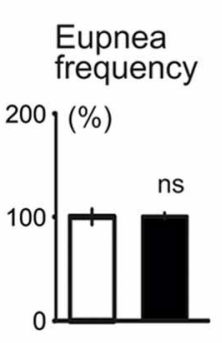

D

Sigh amplitude

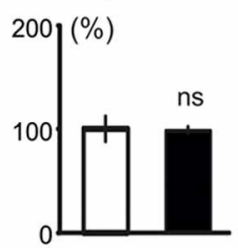

E

Sigh frequency

$\mathbf{F}$

Sigh

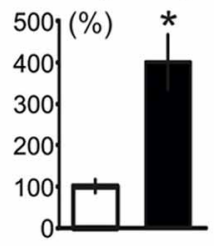

$10 \mathrm{~s}$

$$
\text { duration }
$$

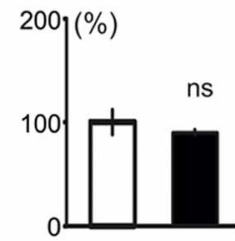

Isoproterenol $20 \mu \mathrm{M}$

FIGURE 4 | Activation of $\beta$-NR modulates fictive sigh. (A) $\int V R G$ activity recorded from a slice under control conditions. (B) Isoproterenol $20 \mu \mathrm{M}$ ( $\beta$-NR agonist) activates $\beta$-NR and increases specifically the frequency of sigh activity. (C-F) Histograms show the effects of isoproterenol on sigh burst frequency (E) without affecting respiratory activity (C), sigh burst amplitude (D), or the sigh burst area (F) $\left({ }^{*} p<0.05, n=10\right)$.

\section{ISOPROTERENOL DID NOT SIGNIFICANTLY AFFECT EXCITATORY SYNAPTIC TRANSMISSION BETWEEN INSPIRATORY NEURONS}

In an attempt to unravel the cellular mechanisms that underlie the action of $\beta$-NR, we investigated the effects of isoproterenol on evoked excitatory synaptic transmission between inspiratory neurons using methodology as previously used by Lieske and Ramirez (2006a). Neurons activated by the contralateral stimulation correspond to monosynaptically connected, glutamatergic preBötC neurons (Bouvier et al., 2010). Isoproterenol had no significant effects on the evoked EPSPs within the preBötC (Figure 5; $n=5$ ). Although, these experiments cannot exclude the possibility that other, unexplored, connections were affected by isoproterenol, our data suggest that the principal effect of $\beta$-NR is not mediated by a general change in excitatory synaptic transmission.

\section{ISOPROTERENOL PREFERENTIALLY MODULATES CADMIUM-INSENSITIVE PACEMAKER NEURONS}

We next explored the modulatory effect on neurons that possess pacemaker bursting properties (Ramirez et al., 2011; Carroll and Ramirez, 2013). In the preBötC region, two types of inspiratory bursting pacemaker mechanisms can be discriminated based on their responses to the general calcium channel blocker cadmium, ( $I_{\text {CAN }}$ or Cadmium-sensitive, and $I_{\text {Nap }}$ or Cadmium-insensitive pacemakers, Thoby-Brisson and Ramirez, 2001; Peña et al., 2004; Viemari et al., 2011). All $I_{\mathrm{CAN}}$ and $I_{\text {Nap }}$ pacemaker neurons $(n=10)$ burst during both fictive eupneic and fictive sigh activity in vitro when embedded in the inspiratory network

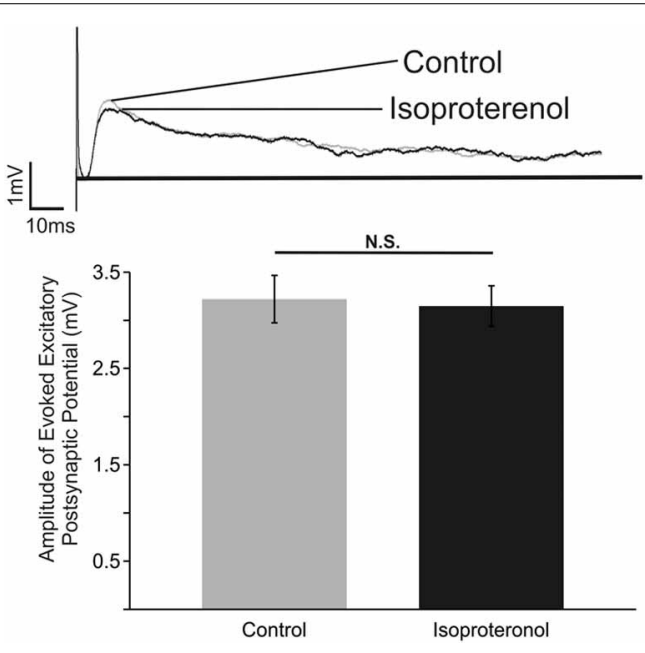

FIGURE 5 | $\beta$-NR modulation does not alter the strength of evoked EPSP in preBötC neurons. Top: Representative traces of an electrically evoked EPSP from an preBötC neuron prior to (Control) and during application of isoproterenol (Isoproterenol). Bottom: Summary of the effect of isoproterenol (20-25 mM) on the amplitude of the evoked EPSP (N.S. $P>0.05 ; n=5$ ).

(Lieske et al., 2000, Figures 6A, 7A). Isoproterenol had no significant effects on the membrane potential of $I_{\text {CAN }}$ pacemaker neurons $(P=0.25)$. Moreover, in all examined, synaptically isolated, $I_{\text {CAN }}$ pacemaker neurons bursting was unaffected by 

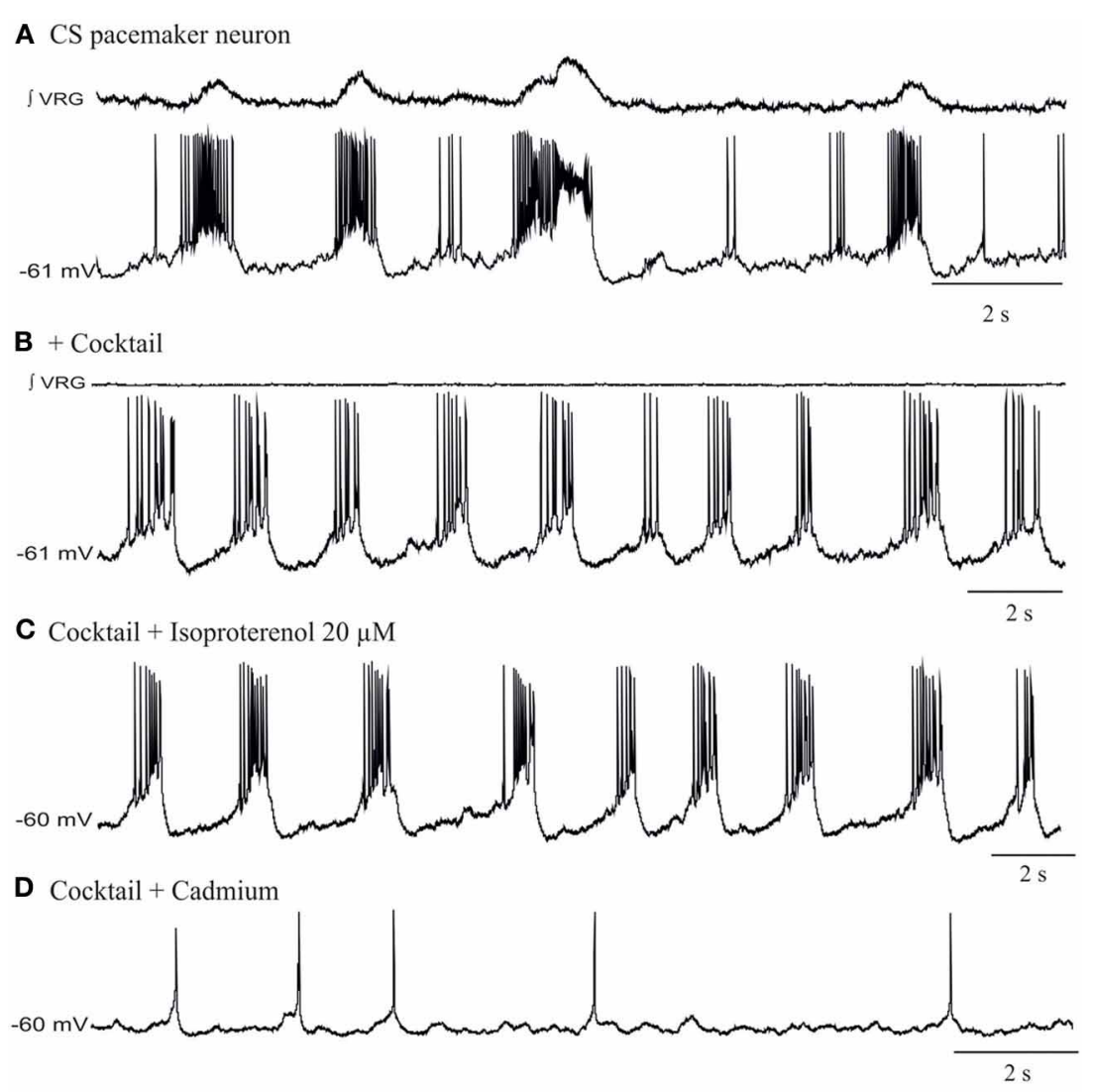

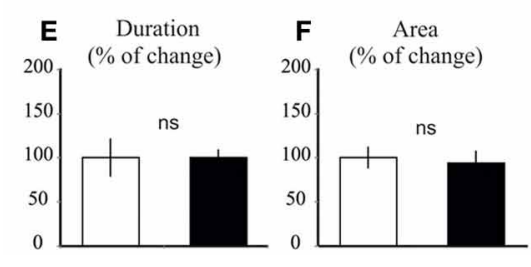

FIGURE 6 | Isoproterenol does not affect the bursting properties of ICAN inspiratory pacemaker neurons. (A) Recording of an inspiratory pacemaker neuron that bursts during fictive sigh activity when embedded in the network. (B) This neuron continues to burst intrinsically in presence of a cocktail that blocks excitatory and inhibitory synaptic transmission (See Methods). (C) Application of isoproterenol $20 \mu \mathrm{M}$ does not significantly change the bursting properties of the ICAN pacemaker

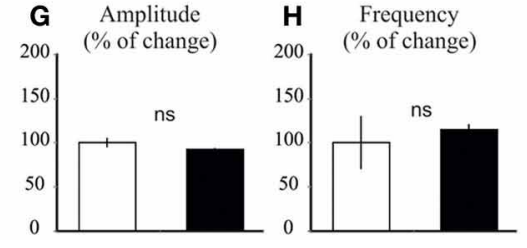

neurons. (D) Application of cadmium $200 \mu \mathrm{M}$ abolishes specifically bursting properties of this pacemaker neuron. Note the neuron continues to spontaneously generate action potentials (E-H) Histograms show no effects of isoproterenol on burst duration (E), area (F), burst amplitude (G), and burst frequency $\mathbf{( H )}$. These effects were quantified by obtaining for each pacemaker neuron the average burst duration, area, and frequency from 15 successive cycles (ns: not significant, $n=4$ ). isoproterenol ( $20 \mu \mathrm{M}, n=4$, Figure 6). No effect was observed on burst amplitude ( $34.6 \pm 2.7$ vs. $33.2 \pm 3.2 \mathrm{mV}$, Figure $6 \mathrm{E})$, burst frequency $(0.33 \pm 0.1$ vs. $0.36 \pm 0.1 \mathrm{~Hz}$, Figure 6F), burst duration $(0.98 \pm 0.2$ vs. $1.02 \pm 0.3 \mathrm{~s}$, Figure $6 \mathbf{G})$ and burst area $(29.35 \pm 1.56$ vs. $27.15 \pm 1.5$, Figure $6 \mathrm{H})$, suggesting that $I_{\text {CAN }}$ pacemaker neurons are unlikely involved in the modulation or the generation of the fictive sigh activity in vitro.

We next investigated the effect of application of isoproterenol on synaptically isolated $I_{\text {Nap }}$ pacemaker neurons (Figures 7B,C,D). In all $I_{\text {Nap }}$ pacemaker neurons tested $(n=6)$ isoproterenol significantly increased the burst frequency $(0.26 \pm$ 0.1 vs. $0.44 \pm 0.1 \mathrm{~Hz}, 173 \pm 13 \%$ of control; $P=0.015$, Wilcoxon rank test; Figure 7F), but not burst amplitude (96 $\pm 4 \%$ of control; Figure 7E), burst duration $(106 \pm 12 \%$ of control; Figure 7G) and burst area (104 $\pm 12 \%$ of control; Figure $7 \mathrm{H}$ ). Further, isoproterenol induced a $1.33 \pm 0.13 \mathrm{mV}$ depolarization in $I_{\text {Nap }}$ pacemaker neurons (data not shown). This specific modulatory action suggests that $I_{\text {Nap }}$ pacemaker neurons may contribute to the modulation of the fictive sigh activity.

\section{RILUZOLE APPLICATION IN THE NETWORK ABOLISHES THE FICTIVE SIGH RHYTHM}

Prior studies demonstrated that the $I_{\mathrm{CAN}}$ bursting mechanism is sensitive to FFA $(50-500 \mu \mathrm{M}$, Peña et al., 2004; Viemari and Ramirez, 2006; Hill et al., 2011), while the $I_{\text {Nap }}$ bursting mechanism is sensitive to riluzole ( $20 \mu \mathrm{M}$; Peña et al., 2004). To test 


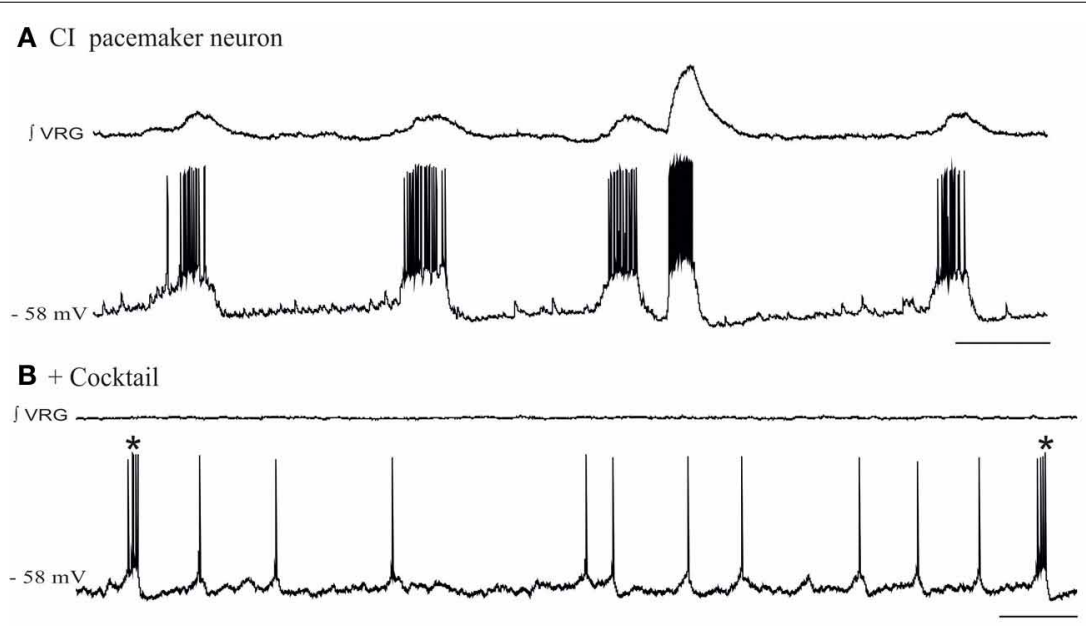

C Cocktail + Isoproterenol $20 \mu \mathrm{M}$
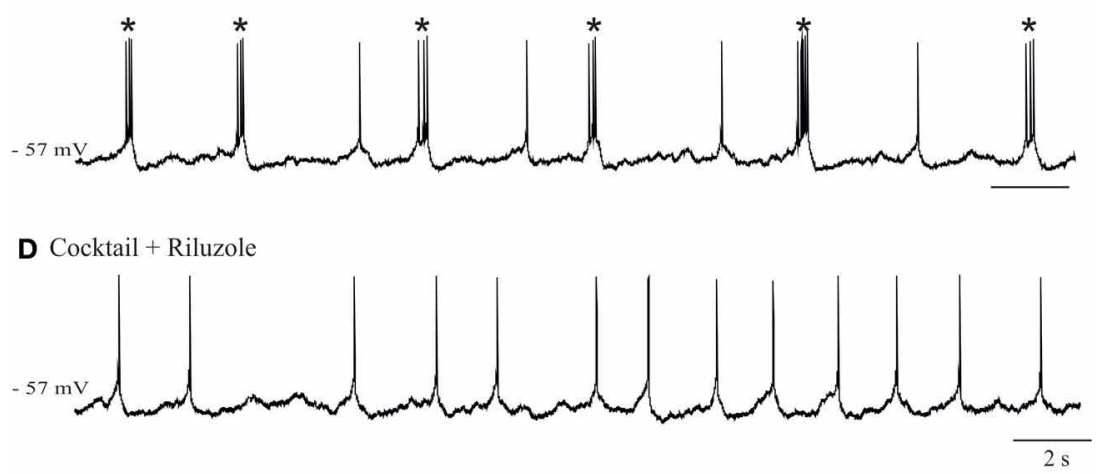
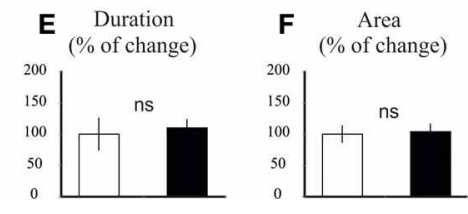

FIGURE 7 | Isoproterenol increases the burst frequency of $\boldsymbol{I}_{\text {Nap }}$ pacemaker neurons. (A) Recording of an inspiratory pacemaker neuron that bursts during fictive sigh activity. (B) This neuron continues to burst in synaptic blockade (cocktail). (C) Application of isoproterenol $20 \mu \mathrm{M}$ increases the burst frequency of $/_{\text {Nap }}$ pacemaker neuron. (D) Application of riluzole
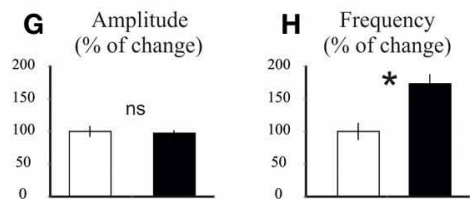

$20 \mu \mathrm{M}$ abolishes the bursting properties of this neuron, but the neuron continues to generate action potentials. Histograms summarize the effects of isoproterenol on burst duration (E), burst area (F), burst amplitude (G), and burst frequency $\mathbf{( H )}$. Note only burst frequency was significantly affected (ns: not significant, $\left.{ }^{*} p<0.05, n=6\right)$. the potential involvement of these two types of bursting mechanisms in mediating the noradrenergic modulation at the network level, we blocked $I_{\mathrm{CAN}}$ with FFA $(50 \mu \mathrm{M}$; Peña et al., 2004; Hill et al., 2011). Application of FFA ( $30 \mathrm{~min}, 50 \mu \mathrm{M})$ alone did not block the generation of spontaneous sigh like activity compared to control (Figures 8A,B), and NE still increased the sigh frequency $(n=9, P<0.01$, Friedman test, Figures $\mathbf{8 C}, \mathbf{D})$. This effect was mediated by the activation of the $\beta$-NRsince application of propanolol $(25 \mu \mathrm{M}, n=5$, data not shown) abolished the increase in sigh frequency.

To explore the potential involvement of $I_{\text {Nap }}$ in the generation of spontaneous sigh activity, we applied riluzole at concentrations that also block bursting in $I_{\text {Nap }}$-dependent pacemaker neurons as previously described (Del Negro et al., 2002, 2005; Peña et al., 2004; Viemari and Ramirez, 2006). Riluzole $(20 \mu \mathrm{M})$ alone abolished fictive sigh activity, but the fictive eupneic activity persisted
(Figures 9A,B). Subsequent application of NE $(20 \mu \mathrm{M}, n=6$, Figure 9A3) did not induce sigh activity and after $5 \mathrm{~min}$ the rhythm completely disintegrated as previously reported (Viemari and Ramirez, 2006). We performed the same set of experiments replacing $\mathrm{NE}$ with isoproterenol, the $\beta$-NR agonist, after riluzole and the sigh activity never came back (Figure 9B3, $n=5$ ) which support our hypothesis that $I_{\text {Nap }}$ mechanisms are important for the modulation of sigh activity.

\section{DISCUSSION}

It is well-documented that the respiratory network simultaneously generates two distinct types of respiratory rhythms within the same anatomical area of the preBötC: "eupneic" and "sigh" rhythmic activity (Lieske et al., 2000). This raises the interesting question how the respiratory network can simultaneously generate rhythms that have two very different cycle periods. The present 

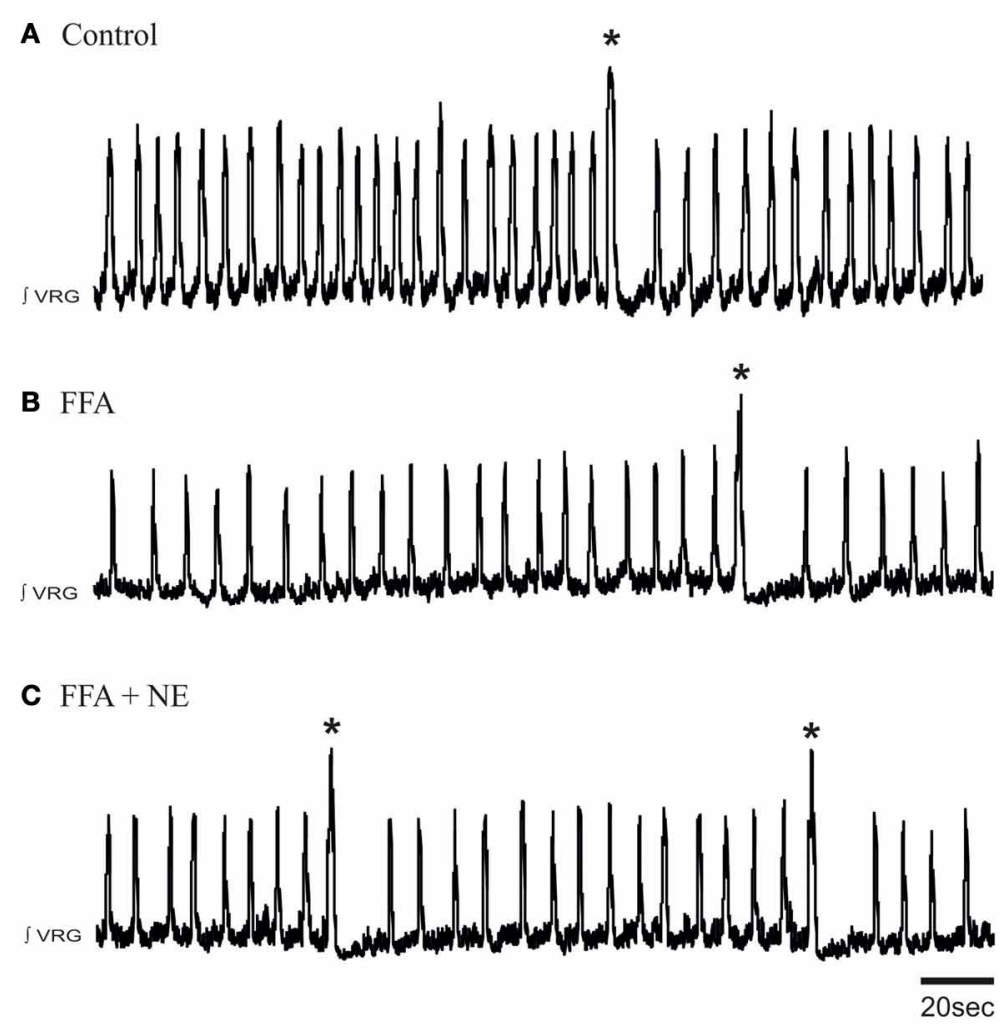

D Sigh frequency $(\mathrm{Hz})$

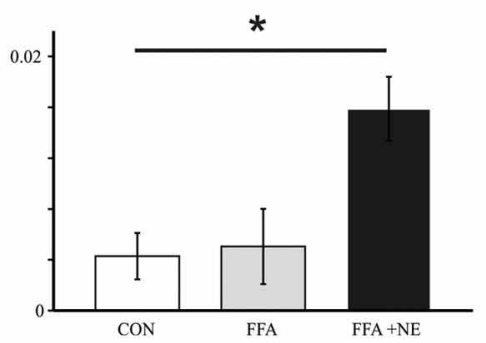

FIGURE 8 | Blockade of $I_{\text {CAN }}$ with FFA does not block the $\boldsymbol{\beta}$-noradrenergic modulation of sigh activity. (A) Fictive sigh activity recorded in a control medullary slice preparation. (B) Application of FFA $(50-500 \mu \mathrm{M})$ does not affect the frequency of sigh activity compared to control. (C) FFA does not prevent the effect of NE on the frequency of sigh activity. (D) Histograms summarize the effects of NE after application of FFA on sigh activity (ns: not significant, $* p<0.05, n=5)$. study revealed a fictive eupneic respiratory rhythm of $\sim 0.18 \mathrm{~Hz}$ and a fictive sigh rhythm of $0.01 \mathrm{~Hz}$. Several lines of evidence suggest that distinct mechanisms contribute to the generation of both rhythms. Fictive sigh rhythmic activity is exquisitely sensitive to the blockade of $\mathrm{P} / \mathrm{Q}$-type voltage-gated calcium channels and the activation of mGluR8 receptors (Lieske and Ramirez, $2006 a, b)$. The frequency of sighs increased in the presence of NMDA blockade, while the frequency, burst duration, and regularity significantly decreased in case of the eupneic activity (Lieske and Ramirez, 2006a,b). We therefore suggested that neurons involved in the generation of sighs possess synaptic properties that are distinct from those critical for the generation of fictive eupneic activity (Lieske and Ramirez, 2006a,b). Fictive sighs and eupneic inspiratory activity are also differentially modulated by neuromodulators (Peña and Ramirez, 2002, 2004; Ramirez and Viemari, 2005; Lieske and Ramirez, 2006a,b; Viemari and Ramirez, 2006; Ruangkittisakul et al., 2008; Tryba et al., 2008). Oxotremorine, a muscarinic agonist, for example activates sighs while inhibiting fictive respiratory activity (Tryba et al., 2008). Here, we show that $\beta$-NR modulation affects specifically the sighs, but not eupneic respiratory activity, both in vivo and in the medullary transverse slice preparation. Although, the results obtained in the slice, are associated with caveats that are shared among many in vitro approaches, it is the in vitro approach that allowed us to further investigate the mechanisms that contribute to the generation/modulation of sigh. Our experiments explored the differential noradrenergic modulation of the two types of bursting mechanisms that have been identified in pacemaker 

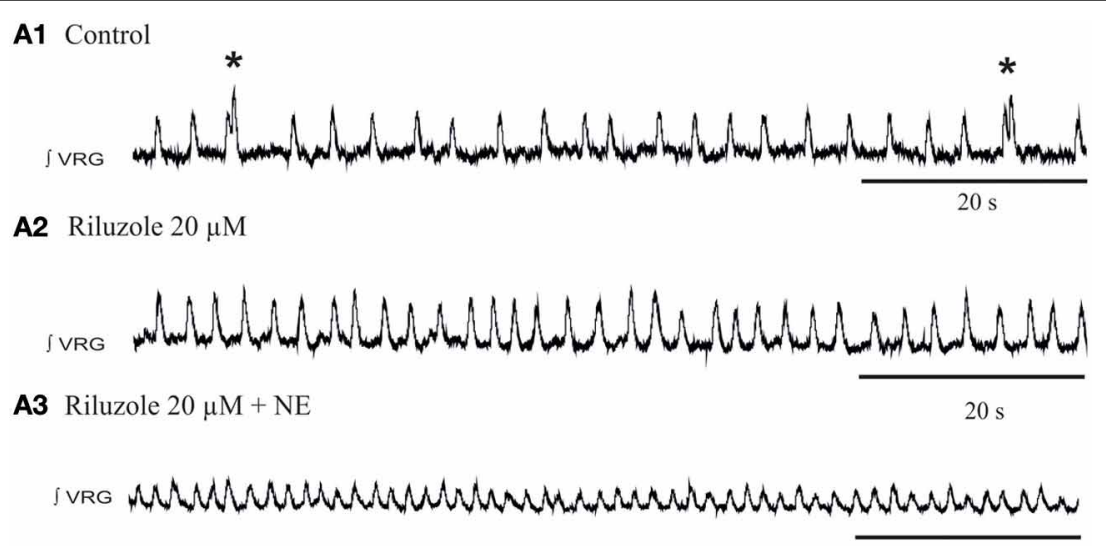

$20 \mathrm{~s}$

B1 Control

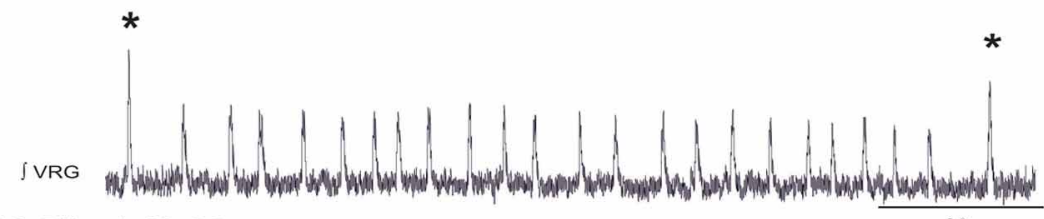

B2 Riluzole $20 \mu \mathrm{M}$

$30 \mathrm{~s}$

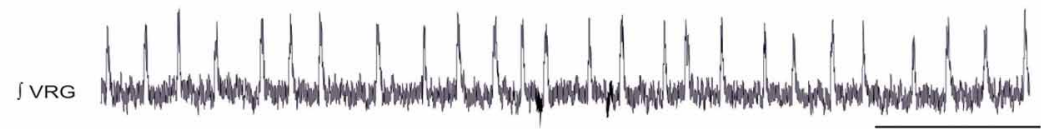

B3 Riluzole $20 \mu \mathrm{M}+$ Isoproterenol $20 \mu \mathrm{M}$

$30 \mathrm{~s}$

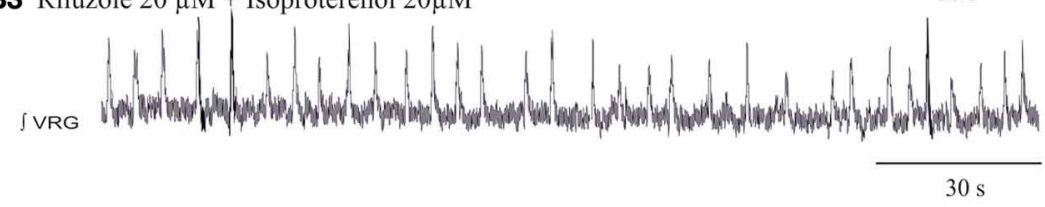

FIGURE 9 | Blockade of the $I_{\text {Nap }}$ blocks the $\beta$-noradrenergic modulation of sigh activity. (A1) $\int V R G$ activity recorded from a slice under control conditions. (A2) Application of riluzole $(20 \mu \mathrm{M})$ abolished the generation of sigh activity. (A3) Riluzole did prevent the effects of NE on the frequency of sigh activity. (B1) $\int \mathrm{VRG}$ activity recorded from a slice under control conditions. (B2) Application of riluzole $(20 \mu \mathrm{M})$ abolished the generation of sigh activity. (B3) Riluzole did block the effect of isoproterenol $(20 \mu \mathrm{M})$ on fictive sigh activity. neurons within the respiratory network: bursting that depends on the presumed activation of $I_{\mathrm{CAN}}$ (e.g., $I_{\mathrm{CAN}}$ pacemakers) and $I_{\text {Nap }}$ (e.g., $I_{\text {Nap }}$ pacemakers) (Thoby-Brisson and Ramirez, 2000, 2001; Peña et al., 2004; Tryba et al., 2006). We showed that $\beta$-NR activation specifically modulated bursting in $I_{\text {Nap }}$ inspiratory pacemaker neurons, but not $I_{\mathrm{CAN}}$-dependent bursting. At the concentrations used to block the $I_{\text {Nap }}$ current and the $\beta$-noradrenergic modulation these inspiratory neurons specifically lose their bursting properties, but continue to spontaneously generate action potentials, suggesting that it is the bursting mechanism that is required for the modulatory effect. However, it is difficult to exclude other potential mechanisms involving the $I_{\mathrm{Nap}}$ current. An increased $I_{\text {Nap }}$ current will likely exert network-wide effects that may ultimately be responsible for the modulatory effect caused by the $\beta$-NR modulation. At this point we also do not know whether the bursting neurons mediate their action via a synaptic excitatory mechanism, since it has been estimated that between 10 and $50 \%$ of pacemaker preBötC neurons may be glycinergic (Morgado-Valle et al., 2010). Synaptic transmission was also not obviously affected by $\beta$-NR activation. This suggests that neither synaptic transmission nor the burst mechanism dependent on $I_{\mathrm{CAN}}$ is a critical determinant of this modulatory effect on sighs. This conclusion is further supported by the finding that FFA at the network level did neither abolish sighs, nor $\beta$ NR modulation of sighs. By contrast, $\beta$-NR modulation increased the burst frequency in $I_{\mathrm{Nap}}$ pacemaker neurons, neurons that rely on a $I_{\text {Nap }}$ dependent burst mechanism. A role of $I_{\text {Nap }}$ in modulating the sigh was also suggested by a study that investigated the effects of a muscarinic agonist oxotremorine. This agonist increased sigh frequency at the network level and specifically enhanced the frequency of a large amplitude, $I_{\mathrm{Nap}}$-dependent and calcium-independent burst mechanism at the level of isolated pacemaker neurons (Tryba et al., 2008).

We previously showed that riluzole applied in the presence of NE worsened the stability of fictive respiration suggesting that the presence of persistent sodium dependent mechanisms is critical 
for generating stable respiratory network activity (Viemari and Ramirez, 2006). However, with respect to this string of arguments it is interesting to find that $\beta$-NR modulation only affects fictive sigh production, and has no effect on the fictive eupneic rhythm. One possibility is that the modulation of the relatively fast bursting $I_{\text {Nap }}$ pacemaker neurons may exert an excitatory effect on the slow sigh rhythm. This finding would be in agreement with computer modeling and experiments performed in a small crustacean network indicating that a slow network oscillator can be controlled by a much faster oscillatory neuron (Nadim et al., 1998). In the present study the effect on the fictive sigh rhythm could be derived from the activation of the bursting $I_{\text {Nap }}$ pacemaker neurons. However, it must be emphasized that the mammalian respiratory network is not nearly as well-understood as the stomatogastric ganglion. Hence such a conclusion must remain largely speculative, and other mechanisms involving the persistent sodium current must also be considered.

A possible explanation for the lack of an effect on eupneic activity is that the depolarization of the $I_{\mathrm{Nap}}$-dependent pacemaker neurons was insufficient for increasing the frequency of fictive eupneic activity, and/or that additional cellular mechanisms stabilize eupneic activity against the modulation of the $I_{\text {Nap }}$-dependent pacemaker neurons. Indeed, this finding would be consistent with our previously published conclusion that respiratory rhythm generation relies not only on one cellular mechanism, but that heterogeneous cellular and network properties contribute to rhythm generation and that manipulating any given mechanism alone is not sufficient to abolish rhythm generation (Peña et al., 2004). It is also consistent with the conclusion that eupnea heavily relies on synaptic mechanisms that involve $I_{\mathrm{CAN}}$ (Rubin et al., 2009).

The $\beta$-NR are known to act via a cAMP cascade, and depending on the system, cAMP can modulate a variety of ionic conductances including sodium current (Schubert et al., 1989; Kirstein et al., 1996; Weigt et al., 1998). At the pre-synaptic level in the amygdala, isoproterenol enhances excitatory transmission via $\beta$-NR (Huang et al., 1996), in the spinal cord it has been shown to increase the excitatory synaptic drive (Tartas et al., 2010). Here, we showed that isoproterenol acts on $\beta$-NR at the postsynaptic level, since isoproterenol excites $I_{\text {Nap }}$ pacemaker neurons that were synaptically isolated. Moreover, $\beta$-NR did not affect excitatory synaptic transmission. Although, our finding is not incompatible with the concept that differential synaptic mechanisms are important in the generation of fictive sigh rhythm as postulated by Lieske and Ramirez (2006a,b), the present finding suggest that $I_{\text {Nap }}$ pacemaker neurons could play a critical role in the modulation of sigh both in vivo and in vitro by $\beta$-NRs.

The present study has also interesting behavioral implications. It is well-established that NE plays a critical role in mediating arousal and promoting wakefulness. Its activating effects involve various subcortical areas including the locus coeruleus, the medial septal, and medial preoptic areas (Berridge et al., 2005). $\beta$-NR located within these regions seem to play a particularly important role in enhancing arousal (Berridge and Morris, 2000; Berridge, 2008). In the present study we describe that the $\beta$-NR agonist isoproterenol acts also on the preBötC, a medullary respiratory network that is critical for the generation of different forms of inspiratory activities. The sigh-specific effect of the $\beta$-NR activation is particularly remarkable, since no effects were observed on eupneic respiratory activity. This is interesting, since it is the sighs that play a critical role in the sequence of events that lead to an arousal response (McNamara et al., 1998; Wulbrand et al., 2008). The majority of spontaneous arousals during sleep occur as a stereotypic sequence that begins with a sigh which is followed by a startle and subsequent cortical arousal (McNamara et al., 2002). Similarly, in response to hypercarbia the arousal response begins with sighs (augmented breaths) that are followed by startles, thrashing limb movements, and subsequently full arousal (Thach and Lijowska, 1996; Lijowska et al., 1997). Thus, a failure to generate sighs during conditions such as hypercarbia or hypoxia may contribute to the events that eventually lead to SIDS (Peña et al., 2004). This hypothesis is supported by finding that sighs and arousals are disturbed in SIDS (Kahn et al., 1988). Previous studies also reported that the noradrenergic system is disturbed in SIDS, which includes evidence such as a diminished tyrosine hydoxylase immunoreactivity within the ventrolateral medulla of SIDS victims (Perrin et al., 1984; Obonai et al., 1998; Sawaguchi et al., 2003). Our results suggest that disturbances in noradrenergic receptors may contribute to abnormal arousal response. Our findings emphasize the need of a better understanding of the differential noradrenergic modulation of subcortical structures that have been implicated in arousal. Taken together, the $\beta$-NR of the sigh activity within the preBötC may contribute to the arousal response.

\section{ACKNOWLEDGMENTS}

This study was supported by NIH grants (RO1 HL/NS60120 and PPG HL090554-01: project 3).

\section{REFERENCES}

Arata, A., Onimaru, H., and Homma, I. (1998). The adrenergic modulation of firings of respiratory rhythm-generating neurons in medulla-spinal cord preparation from newborn rat. Exp. Brain Res. 119, 399-408. doi: $10.1007 / \mathrm{s} 002210050355$

Bartlett, D. (1971). Origin and regulation of spontaneous deep breaths. Respir. Physiol. 12, 230. doi: 10.1016/0034-5687(71)90055-7

Bedogni, F., Hodge, R. D., Elsen, G. E., Nelson, B. R., Daza, R. A., Beyer, R. P., et al. (2010). Tbrl regulates regional and laminar identity of postmitotic neurons in developing neocortex. Proc. Natl. Acad. Sci. U.S.A. 107, 13129-13134. doi: 10.1073/pnas.1002285107

Bendixen, H. H., Smith, G. M., and Mead, J. (1964). Pattern of ventilation in young adults. J. Appl. Physiol. 19, 195.

Berridge, C. W. (2008). Noradrenergic modulation of arousal. Brain Res. Rev. 58, 1-17. doi: 10.1016/j.brainresrev.2007.10.013

Berridge, C. W., and Morris, M. F. (2000). Amphetamine-induced activation of forebrain EEG is prevented by noradrenergic beta-receptor blockade in the halothane-anesthetized rat. Psychopharmacology (Berl.) 148, 307-313. doi: 10.1007/s002130050055

Berridge, C. W., Stellick, R. L., and Schmeichel, B. E. (2005). Wakepromoting actions of medial basal forebrain beta(2) receptor stimulation. Behav. Neurosci. 119, 743-751. doi: 10.1037/0735-7044.119. 3.743

Bouvier, J., Thoby-Brisson, M., Renier, N., Dubreuil, V., Ericson, J., Champagnat, J., et al. (2010). Hindbrain interneurons and axon guidance signaling critical for breathing. Nat. Neurosci. 13, 1066-1074. doi: 10.1038/nn.2622

Carroll, M. S., and Ramirez, J. M. (2013). Cycle-by-cycle assembly of respiratory network activity is dynamic and stochastic. J. Neurophysiol. 109, 296-305. doi: 10.1152/jn.00830.2011 
Cherniack, N. S., Voneuler, C., Glogowska, M., and Homma, I. (1981). Characteristics and rate of occurrence of spontaneous and porvoked augmented breaths. Acta Physiol. Scand. 111, 349-360. doi: 10.1111/j.17481716.1981.tb06747.x

Crone, S. A., Viemari, J. C., Droho, S., Mrejeru, A., Ramirez, J. M., and Sharma, K. (2012). Irregular breathing in mice following genetic ablation of V2a neurons. J. Neurosci. 32, 7895-7906. doi: 10.1523/JNEUROSCI.0445-12.2012

Del Negro, C. A., Koshiya, N., Butera, R. J. Jr., and Smith, J. C. (2002). Persistent sodium current, membrane properties and bursting behavior of pre-Bötzinger complex inspiratory neurons in vitro. J. Neurophysiol. 88, 2242-2250. doi: 10.1152/jn.00081.2002

Del Negro, C. A., Morgado-Valle, C., Hayes, J. A., Mackay, D. D., Pace, R. W., Crowder, E. A., et al. (2005). Sodium and calcium current-mediated pacemaker neurons and respiratory rhythm generation. J. Neurosci. 25, 446-453. doi: 10.1523/JNEUROSCI.2237-04.2005

Doi, A., and Ramirez, J. M. (2010). State-dependent interactions between excitatory neuromodulators in the neuronal control of breathing. J. Neurosci. 30, 8251-8262. doi: 10.1523/JNEUROSCI.5361-09.2010

Guinamard, R., Simard, C., and Del Negro, C. (2013). Flufenamic acid as an ion channel modulator. Pharmacol. Ther. 138, 272-284. doi: 10.1016/j.pharmthera.2013.01.012

Glogowska, M., Widdicom, J., Winning, A. J., and Richards, P. (1972). Role of vagus nerves, peripheral chemoreceptors and other afferent pathways in genesis of augmented breaths in cats and rabbits. Respir. Physiol. 16, 179. doi: 10.1016/0034-5687(72)90050-3

Gray, P. A., Rekling, J. C., Bocchiaro, C. M., and Feldman, J. L. (1999). Modulation of respiratory frequency by peptidergic input to rhythmogenic neurons in the preBotzinger complex. Science 286, 1566-1568. doi: 10.1126/science.286.5444.1566

Guyenet, P. G., Sevigny, C. P., Weston, M. C., and Stornetta, R. L. (2002). Neurokinin-1 receptor-expressing cells of the ventral respiratory group are functionally heterogeneous and predominantly glutamatergic. J. Neurosci. 22, 3806-3816.

Hevner, R. F., Shi, L., Justice, N., Hsueh, Y., Sheng, M., Smiga, S., et al. (2001). Tbr1 regulates differentiation of the preplate and layer 6. Neuron 29, 353-366. doi: 10.1016/S0896-6273(01)00211-2

Hill, A. A., Garcia, A. J., Zanella, S., Upadhyaya, R., and Ramirez, J. M. (2011). Graded reductions in oxygenation evoke graded reconfiguration of the isolated respiratory network. J. Neurophysiol. 105, 625-639. doi: 10.1152/jn.00237.2010

Huang, C. C., Hsu, K. S., and Gean, P. W. (1996). Isoproterenol potentiates synaptic transmission primarily by enhancing presynaptic calcium influx via $\mathrm{P}$ - and/or Q-type calcium channels in the rat amygdala. J. Neurosci. 16, 1026-1033.

Kahn, A., Blum, D., Rebuffat, E., Sottiaux, M., Levitt, J., Bochner, A., et al. (1988). Polysomnographic studies of infants who subsequently died of sudden infant death syndrome. Pediatrics 82, 721-727.

Kirstein, M., Eickhorn, R., Kochsiek, K., and Langenfeld, H. (1996). Dosedependent alteration of rat cardiac sodium current by isoproterenol: Results from direct measurements on multicellular preparations. Pflugers Arch. 431, 395-401. doi: 10.1007/BF02207277

Koch, H., Zanella, S., Elsen, G. E., Smith, L., Doi, A., Garcia, A. J., et al. (2013). Stable respiratory activity requires both $\mathrm{P} / \mathrm{Q}$-type and $\mathrm{N}$-type voltage-gated calcium channels. J. Neurosci. 33, 3633-3645. doi: 10.1523/JNEUROSCI.639011.2013

Lieske, S. P., and Ramirez, J. M. (2006a). Pattern-specific synaptic mechanisms in a multifunctional network. I. Effects of alterations in synapse strength. J. Neurophysiol. 95, 1323-1333. doi: 10.1152/jn.00505.2004

Lieske, S. P., and Ramirez, J. M. (2006b). Pattern-specific synaptic mechanisms in a multifunctional network. II. Intrinsic modulation by metabotropic glutamate receptors. J. Neurophysiol. 95, 1334-1344. doi: 10.1152/jn.00506.2004

Lieske, S. P., Thoby-Brisson, M., Telgkamp, P., and Ramirez, J. M. (2000). Reconfiguration of the neural network controlling multiple breathing patterns: eupnea, sighs and gasps. Nat. Neurosci. 3, 600-607. doi: 10.1038/75776

Lijowska, A. S., Reed, N. W., Chiodini, B. A. M., and Thach, B. T. (1997). Sequential arousal and airway-defensive behavior of infants in asphyxial sleep environments. J. Appl. Physiol. 83, 219-228.

Marshall, J. M., and Metcalfe, J. D. (1988). Cardiovascular changes associated with augmented breaths in normoxia and hypoxia in the rat. J. Physiol. 400, 15-27.

Matsumoto, S., Takeda, M., Saiki, C., Takahashi, T., and Ojima, K. (1997). Effects of vagal and carotid chemoreceptor afferents on the frequency and pattern of spontaneous augmented breaths in rabbits. Lung 175, 175-186. doi: 10.1007/PL00007565

McNamara, F., Lijowska, A. S., and Thach, B. T. (2002). Spontaneous arousal activity in infants during NREM and REM sleep. J. Physiol. 538, 263-269. doi: 10.1113/jphysiol.2001.012507

McNamara, F., Wulbrand, H., and Thach, B. T. (1998). Characteristics of the infant arousal response. J. Appl. Physiol. 85, 2314-2321.

Morgado-Valle, C., Baca, S. M., and Feldman, J. L. (2010). Glycinergic pacemaker neurons in PreBotzinger complex of neonatal mouse. J. Neurosci. 30, 3634-3639. doi: 10.1523/JNEUROSCI.3040-09.2010

Nadim, F., Manor, Y., Nusbaum, M. P., and Marder, E. (1998). Frequency regulation of a slow rhythm by a fast periodic input. J. Neurosci. 18, 5053-5067.

Neher, E. (1992). Correction for liquid potentials in patch clamp expreiments. Methods Enzymol. 207, 123-131. doi: 10.1016/0076-6879(92)07008-C

Obonai, T., Yasuhara, M., Nakamura, T., and Takashima, S. (1998). Catecholamine neurons alteration in the brainstem of sudden infant death syndrome victims. Pediatrics 101, 285-288. doi: 10.1542/peds.101.2.285

Orem, J., and Trotter, R. H. (1993). Medullary respiratory neuronal-activity during augmented breaths in intact unanesthetized cats. J. Appl. Physiol. 74, 761-769.

Pagliardini, S., Ren, J., and Greer, J. J. (2003). Ontogeny of the pre-Botzinger complex in perinatal rats. J. Neurosci. 23, 9575-9584.

Peña, F., Parkis, M. A., Tryba, A. K., and Ramirez, J. M. (2004). Differential contribution of pacemaker properties to the generation of respiratory rhythms during normoxia and hypoxia. Neuron. 43, 105-117. doi: 10.1016/j.neuron.2004.06.023

Peña, F., and Ramirez, J. M. (2002). Endogenous activation of serotonin-2A receptors is required for respiratory rhythm generation in vitro. J. Neurosci. 22, 11055-11064.

Peña, F., and Ramirez, J. M. (2004). Substance P-mediated modulation of pacemaker properties in the mammalian respiratory network. J. Neurosci. 24, 7549-7556. doi: 10.1523/JNEUROSCI.1871-04-2004

Perrin, D. G., Becker, L. E., Madapallimatum, A., Cutz, E., Bryan, A. C., and Sole, M. J. (1984). Sudden infant death syndrome and noradrenaline content. Lancet 2, 535-537. doi: 10.1016/S0140-6736(84)90763-3

Ramirez, J. M., Koch, H., Garcia, A. J., Doi, A., and Zanella, S. (2011). The role of spiking and bursting pacemakers in the neuronal control of breathing. J. Biol. Phys. 37, 241-261. doi: 10.1007/s10867-011-9214-z

Ramirez, J. M., Quellmalz, U. J. A., and Richter, D. W. (1996). Postnatal changes in the mammalian respiratory network as revealed by the transverse brainstem slice of mice. J. Physiol. 491, 799-812.

Ramirez, J. M., and Viemari, J. C. (2005). Determinants of inspiratory activity. Respir. Physiol. Neurobiol. 147, 145-157. doi: 10.1016/j.resp.2005.05.003

Ruangkittisakul, A., Panaitescu, B., and Ballanyi, K. (2011). K+ and Ca2+ dependence of inspiratory-related rhythm in novel "calibrated" mouse brainstem slices. Respir. Physiol. Neurobiol. 175, 37-48. doi: 10.1016/j.resp.2010.09.004

Ruangkittisakul, A., Schwarzacher, S. W., Secchia, L., Ma, Y., Bobocea, N., Poon, B. Y., et al. (2008). Generation of eupnea and sighs by a spatiochemically organized inspiratory network. J. Neurosci. 28, 2447-2458. doi: 10.1523/JNEUROSCI.1926-07.2008

Rubin, J. E., Hayes, J. A., Mendenhall, J. L., and Del Negro, C. A. (2009). Calciumactivated nonspecific cation current and synaptic depression promote networkdependent burst oscillations. Proc. Natl. Acad. Sci. U.S.A. 106, 2939-2944. doi: 10.1073/pnas.0808776106

Sawaguchi, T., Ozawa, Y., Patricia, F., Kadhim, H., Groswasser, J., Sottlaux, M., et al. (2003). Catecholaminergic neurons in the brain-stem and sleep apnea in SIDS victims. Early Hum. Dev. 75, S41-S50. doi: 10.1016/j.earlhumdev.2003. 08.007

Schubert, B., Vandongen, A. M. J., Kirsch, G. E., Brown, A. M. (1989). Betaadrenergic inhibition of cardiac sodium-channels by dual G-protein pathways. Science 245, 516-519. doi: 10.1126/science.2547248

Schwarzacher, S. W., Rub, U., and Deller, T. (2011). Neuroanatomical characteristics of the human pre-Botzinger complex and its involvement in neurodegenerative brainstem diseases. Brain 134, 24-35. doi: 10.1093/brain/awq327

Seutin, V., and Johnson, S. W. (1999). Recent advances in the pharmacology of quaternary salts of bicuculline. Trends Pharmacol. Sci. 20, 268-270. doi: 10.1016/S0165-6147(99)01334-6

Takeda, M., and Matsumoto, S. (1998). Effects of NMDA and non-NMDA receptor antagonists on the medullary inspiratory neuronal activity during spontaneous augmented breaths in anesthetized rats. Brain Res. 781, 194-201. doi: 10.1016/S0006-8993(97)01249-3 
Tan, W. B., Janczewski, W. A., Yang, P., Shao, X. M., Callaway, E. M., and Feldman, J. L. (2008). Silencing preBotzinger Complex somatostatin-expressing neurons induces persistent apnea in awake rat. Nat. Neurosci. 11, 538-540. doi: 10.1038/nn.2104

Tartas, M., Morin, F., Barriere, G., Goillandeau, M., Lacaille, J. C., Cazalets, J. R., et al. (2010). Noradrenergic modulation of intrinsic and synaptic properties of lumbar motoneurons in the neonatal rat spinal cord. Front. Neural Circuits 4:4. doi: $10.3389 /$ neuro.04.004.2010

Telgkamp, P., and Ramirez, J. M. (1999). Differential responses of respiratory nuclei to anoxia in rhythmic brain stem slices of mice. J. Neurophysiol. 82, 2163-2170.

Thach, B. T. (2002). Graded arousal responses in infants: advantages and disadvantages of a low threshold for arousal. Sleep Med. 3, S37-S40. doi: 10.1016/S13899457(02)00162-4

Thach, B. T., and Lijowska, A. (1996). Arousals in infants. Sleep 19, S271-S273.

Thoby-Brisson, M., and Ramirez, J. M. (2000). Role of inspiratory pacemaker neurons in mediating the hypoxic response of the respiratory network in vitro. J. Neurosci. 20, 5858-5866.

Thoby-Brisson, M., and Ramirez, J. M. (2001). Identification of two types of inspiratory pacemaker neurons in the isolated respiratory neural network of mice. J. Neurophysiol. 86, 104-112.

Tryba, A. K., Pena, F., Lieske, S. P., Viemari, J. C., Thoby-Brisson, M., and Ramirez, J. M. (2008). Differential modulation of neural network and pacemaker activity underlying eupnea and sigh-breathing activities. J. Neurophysiol. 99, 2114-2125. doi: 10.1152/jn.01192.2007

Tryba, A. K., Pena, F., and Ramirez, J. M. (2003). Stabilization of bursting in respiratory pacemaker neurons. J. Neurosci. 23, 3538-3546.

Tryba, A. K., Pena, F., and Ramirez, J. M. (2006). Gasping activity in vitro: a rhythm dependent on 5-HT2A receptors. J. Neurosci. 26, 2623-2634. doi: 10.1523/JNEUROSCI.4186-05.2006

Viemari, J. C. (2008). Noradrenergic modulation of the respiratory neural network. Respir. Physiol. Neurobiol. 164, 123-130. doi: 10.1016/j.resp.2008.06.016

Viemari, J. C., Bevengut, M., Coulon, P., and Hilaire, G. (2004). Nasal trigeminal inputs release the A5 inhibition received by the respiratory rhythm generator of the mouse neonate. J. Neurophysiol. 91, 746-758. doi: 10.1152/jn.01153.2002

Viemari, J. C., Garcia, A. J., Doi, A., and Ramirez, J. M. (2011). Activation of alpha2 noradrenergic receptors is critical for the generation of fictive eupnea and fictive gasping inspiratory activities in mammals in vitro. Eur. J. Neurosci. 33, 2228-2237. doi: 10.1111/j.1460-9568.2011.07706.x

Viemari, J. C., and Ramirez, J. M. (2006). Norepinephrine differentially modulates different types of respiratory pacemaker and nonpacemaker neurons. J. Neurophysiol. 95, 2070-2082. doi: 10.1152/jn.01308.2005

Viemari, J. C., Roux, J. C., Tryba, A. K., Saywell, R., Burnet, H., Pena, F., et al. (2005). Mecp2 deficiency disrupts norepinephrine and respiratory systems in mice. J. Neurosci. 25, 11521-11530. doi: 10.1523/JNEUROSCI.437305.2005

Weigt, H. U., Kwok, W. M., Rehmert, G. C., and Bosnjak, Z. J. (1998). Modulation of the cardiac sodium current by inhalational anesthetics in the absence and presence of beta-stimulation. Anesthesiology 88, 114-124. doi: 10.1097/00000542-199801000-00019

Wulbrand, H., McNamara, F., and Thach, B. T. (2008). The role of arousal related brainstem reflexes in causing recovery from upper airway occlusion in infants. Sleep 31, 833-840.

Zanella, S., Roux, J. C., Viemari, J. C., and Hilaire, G. (2006). Possible modulation of the mouse respiratory rhythm generator by A1/C1 neurones. Respir. Physiol. Neurobiol. 153, 126-138. doi: 10.1016/j.resp.2005.09.009

Conflict of Interest Statement: The authors declare that the research was conducted in the absence of any commercial or financial relationships that could be construed as a potential conflict of interest.

Received: 01 July 2013; accepted: 23 October 2013; published online: 12 November 2013.

Citation: Viemari J-C, Garcia AJ III, Doi A, Elsen G and Ramirez J-M (2013) $\beta$-noradrenergic receptor activation specifically modulates the generation of sighs in vivo and in vitro. Front. Neural Circuits 7:179. doi: 10.3389/fncir.2013.00179 This article was submitted to the journal Frontiers in Neural Circuits.

Copyright (C) 2013 Viemari, Garcia, Doi, Elsen and Ramirez. This is an open-access article distributed under the terms of the Creative Commons Attribution License (CC BY). The use, distribution or reproduction in other forums is permitted, provided the original author(s) or licensor are credited and that the original publication in this journal is cited, in accordance with accepted academic practice. No use, distribution or reproduction is permitted which does not comply with these terms. 